\title{
Séminaire de Chicoutimi 1873-1973 : coup d'oeil sur le siècle écoulé
}

\section{Ovide-D. Simard}

Volume 40, 1973

URI : https://id.erudit.org/iderudit/1007251ar

DOI : https://doi.org/10.7202/1007251ar

Aller au sommaire du numéro

Éditeur(s)

Les Éditions Historia Ecclesiæ Catholicæ Canadensis Inc.

ISSN

0318-6172 (imprimé)

1927-7067 (numérique)

Découvrir la revue

Citer cet article

Simard, O.-D. (1973). Séminaire de Chicoutimi 1873-1973 : coup d'oeil sur le siècle écoulé. Sessions d'étude - Société canadienne d'histoire de l'Église catholique, 40, 125-129. https://doi.org/10.7202/1007251ar

Tous droits réservés @ Les Éditions Historia Ecclesiæ Catholicæ Canadensis Inc., 1974
Ce document est protégé par la loi sur le droit d'auteur. L'utilisation des services d'Érudit (y compris la reproduction) est assujettie à sa politique d'utilisation que vous pouvez consulter en ligne.

https://apropos.erudit.org/fr/usagers/politique-dutilisation/ 


\section{Séminaire de Chicoutimi 1873-1973 Coup d'œil sur le siècle écoulé}

Comme je suis le plus ancien Supérieur vivant, il me revient, je crois, de jeter un coup d'œil, oh! très furtif, sur le passé, jusqu'à la fin de mon supériorat.

Je divise le siècle en trois périodes. J'appelle la première: période de l'héroösme. Elle va de 1873 à 1914: 41 ans. La deuxième est la période de stabilité, de 1914 à vers 1960: 46 ans. La troisième est la périodc de. révolution, de 1960 à 1973: 13 ans. C'est la plus courte, mais, même tranquille, une révolution opère toujours rondement.

Je suis entré au Séminaire en 1907, et j'ai terminé mon cours en 1914. J'ai donc fait mes études durant la période héroïque.

C'était encore le temps du personnel réduit, du moins quant au nombre, car la qualité y était à un degré remarquable.

C'était le temps où l'on cassait la glace dans les bassins le matin. Le temps de la tranche de pain sec à 4 heures. Et dire qu'on avait hâte! Comme on le répète souvent dans les Relations des Jésuites, la faim est le plus merveilleux des assaisonnements. Le temps où, avec un dollar, on voyait à ses petites dépenses de septembre à janvier.

Et dire aussi qu'on était loin d'être malheureux! Le train des familles alors était très modeste. Aussi les enfants gâtés étaient rares, et s'il en venait au Séminaire, ils n'y collaient pas. Un sacrifice de plus ou de moins, ça n'a vait pas d'importance. Mais le moindre plaisir en avait beaucoup.

Dans ce monde-là, rien ne coûtait cher, pas même le bonheur. Dans la société de consommation, tout coûte cher, le bonheur plus que tout le reste, du moins si on en juge par le nombre des malcontents.

Cette première période s'achève dans les ruines de l'incendie de 1912, qui dévore tout un pâté de maisons entre les rues Racine et JacquesCartier, et complète son menu par la Cathédrale, le Couvent du BonPasteur et le Séminaire. La Commission scolaire de Chicoutimi vient au secours du Conseil du Séminaire en mettant à sa disposition l'Académie Commerciale, sise au centre de la ville et maintenant démolie. Le geste est magnifique. Les cours reprennent en septembre avec très peu de retard. On devine cependant que dans une maison pas du tout conçue pour un 
pensionnat, accommodée vaille que vaille et avec le moins de frais possible, et remplie à craquer, on devine... que l'héroïsme a eu beau jeu pour établir des records.

En 1914, nous entrons dans un nouvel édifice: le Séminaire actuel, tel qu'il est aujourd'hui, du moins à l'extérieur. Pour le confort, c'est un progrès considérable. Ensemble plus fonctionnel, espaces plus généreux, meilleure circulation de l'air, chaleur convenable dans les mauvaises saisons, et puis un quelque chose de beaucoup plus gai. Il y a l'eau courante pour la toilette du matin, et même des douches, chose rare à l'époque. Pour assez d'élèves, c'est presque du luxe, comparé à ce qu'ils ont chez eux.

De 1914 à 1954, année où j'ai quitté, des changements, il y en a eu tout le long. Mais ils se sont présentés un par un, et chacun est un détail qui ne modifie pas tellement l'ensemble. C'est pourquoi je dis: période de stabilité.

Voici les principaux changements. Je les énumère sans trop d'ordre ni de précision.

Je note trois constructions: l'aile de l'est, au centre un corps de bâtisse orienté vers le sud, et un étage ajouté à l'aile de l'ouest.

Aussi trois changements disciplinaires. Les vacances du jour de l'An sont doublées par l'addition de la semaine de Noël. Le fumage est permis tous les jours. Les femmes s'étant mises à fumer, la chose est jugée d'usage universel. Le vénérable "capot d'écolier" reçoit son coup de mort, supplanté par le blazer.

Domaine des études. Les mathématiques sont introduites dans les classes de grammaires et de lettres. Le cours classique était de six ans. Par deux fois on ajoute une année, pour être sur le pied des autres institutions.

Le personnel. Entre 1914 et 1925, il a pratiquement doublé. Dès lors le Séminaire est en mesure de maintenir aux études supérieures plusieurs sujets à la fois, et cela de façon continue. Et il ne se limite plus à des qualifications en philosophie et en théologie. Sciences et lettres entrent dans le jeu, non en parents pauvres, mais en véritables partenaires.

Cette situation permet d'atteindre un autre objectif visé depuis longtemps : libérer les ecclésiastiques de tout travail au Petit Séminaire, et les laisser tout à leurs études et à leur formation. Ils avaient rendu des services précieux, nécessaires même, mais non sans inconvénients pour eux. mêmes et pour le diocèse. Il était temps de corriger cette situation. 
Quelques années plus tard, cependant, un problème s'est posé. L'Action Catholique, en multipliant ses mouvements, réclamait de plus en plus de personnel. Par ailleurs, le développement urbain amenait la création de nouvelles paroisses à un rythme plutôt rapide. Force fut de faire appel au Séminaire. Mais là aussi les besoins grandissaient puisque le nombre des élèves augmentait. Il ne restait qu'une solution: avoir recours à des professeurs laïcs, comme on le faisait ailleurs. Disons que, dans l'ensemble, les nouveaux venus ont fait bonne figure. Plusieurs y ont trouvé une carrière.

L'ère de l'automobile et des routes carrossables a produit un changement d'une autre nature, et profond, celui-là.

Durant un bon demi-siècle, le Séminaire a été une maison close. C'était l'internat à l'état pur. Les parloirs étaient les pièces les moins fréquentées. Pour ma part, en onze années d'études au Petit et au Grand Séminaire, j’y suis allé deux fois. Même les élèves de paroisses voisines, s'ils étaient mieux partagés, n'étaient pas gâtés du tout; car venir de Jonquière ou de Bagotville prenait autant de temps que venir de la Baie Saint-Paul ou de Dolbeau aujourd'hui.

Mais l'automobile et les routes, en quelques années, ont eu raison de cette situation. Chaque dimanche, ce fut l'invasion. Parloirs, classes, même les dortoirs étaient grouillants de monde.

Premier résultat : le dimanche, jusque-là jour ouvrable, est devenu jour de congé, ou à peu près.

Deuxième résultat: les élèves ont eu vue sur la place publique. D'autres influences que les nôtres ont joué sur leur mentalité. Dans l'ensemble, c'était probablement un bien. Mais notre tâche n'en a pas été simplifiée, c'est certain.

Troisième résultat: l'externat, jusque-là statut d'exception, est devenu possible à toute la périphérie, de Jonquière à la Baie des $\mathrm{Ha}$ ! $\mathrm{Ha}$ ! Du coup les études classiques étaient mises à la portée d'un plus grand nombre.

Mais le vrai coup de barre dans cette direction a été la création des Sections Classiques dans les principaux centres du diocèse. C'est $\mathbf{M}^{\mathrm{gr}}$ Georges Melançon qui en a eu l'idée. En quelques années il y en eut une dizaine. Chacune devait recruter son personnel, mais académiquement elles étaient dépendantes du Séminaire, sous la direction immédiate du Préfet des Études. Elles comptèrent bientôt plusieurs centaines d'élèves. C'est dire combien la mesure était opportune. 
Un dernier point: les contacts avec les autres institutions. Sur ce terrain la géographie ne nous aidait pas. Durant le premier demi-siècle, la seule occasion de contact était la correction du baccalauréat à Québec. Nous partions deux ou trois professeurs et, durant une semaine, nous vivions a vec d'autres professeurs, venus de tous les coins. De quoi était-il question dans nos récréations et nos soirées? De ce qui se faisait dans chacune de nos maisons, de nos problèmes, des expériences tentées ici et là... Déjà c'était précieux pour nous orienter, nous rassurer.

Dans la suite s'organisèrent des rencontres de titulaires d'une même fonction : Supérieurs, Préfets des Études, Directeurs des Élèves ou Préfets de Discipline, Directeurs spirituels. Même si elles étaient assez irrégulières, c'était une amélioration très valable. Mais le grand pas n'était pas fait.

Il le fut en 1951, année où a été fondée la Fédération des Collèges classiques. Au départ quelques institutions: Collège Saint-Laurent, Externat classique de Sainte-Croix, les Séminaire de Trois-Rivières, de Nicolet, de Chicoutimi. Le ralliement des autres fut assez laborieux, certains Évêques ayant de l'inquiétude... Dieu sait pourtant si nous n'avions pas du tout l'envie d'embêter l'Épiscopat!

La Providence vint à notre secours. $\mathrm{M}^{\mathrm{gr}}$ Martin, de Nicolet, nous faisait tout à fait confiance. Quand nous avions à traiter avec l'Assemblée des Évêques, c'est dans son bureau que se préparaient les pièces à présenter. Et il se chargeait de les faire passer. Il fut si bon avocat que jamais rien ne fut bloqué.

Le gros travail des premières années a été le Mémoire à présenter à la Commission Tremblay. Nous avions comme conseiller juridique un jeune avocat qui depuis a fait parler de lui : Paul Gérin-Lajoie.

Je laisse à d'autres de dire ce qui s'est passé après, puisque je n'étais plus là. Je note simplement pour l'histoire : l'âme de la Fédération a été le R.P. Lalande, des Pères de Sainte-Croix, aujourd'hui général de sa Communauté. La Fédération est sortie de sa tête presque toute faite. Les autres ont eu le mérite de le suivre.

Période de stabilité, ai-je dit en parlant des années 1914 à 1960 . Période de progrès aussi. Tout en restant le même, le Séminaire s'adapte, ajoute, perfectionne, élargit son action. Ainsi l'arbre, tout en restant le même, insensiblement grossit, s'élève, s'élargit. C'est la grande différence entre la dernière période qui, en peu de temps, met en question l'existence même de l'institution. C'est pour cela que je l'appelle la période révolutionnaire. 
Je m'arrête. Et je m'excuse. J'ai cru qu'une vue d'ensemble, même imparfaite, était nécessaire. Sans elle, je trouvais que je n'avais rien à dire. Et je voyais les autres dans mon cas.

O.D. Simard, ptre, v.h., p.d., Diplômé en études supérieures françaises, Supérieur du Séminaire, 1950-1954, Chicoutimi, P.Q. 